\title{
Thermal and electric Characteristics of High-power Short-duration Radiofrequency Ablation and Standard Radiofrequency Ablation: A Computer Simulation Study
}

\section{Kaihao Gu}

Fudan University https://orcid.org/0000-0001-7459-8891

Shengjie Yan

Fudan University

Xiaomei Wu ( $\square$ xiaomeiwu@fudan.edu.cn )

Shanghai Engineering Research Center of Assistive Devices, Shanghai, China https://orcid.org/00000002-4937-7680

Research

Keywords: Cardiac RF ablation, High-power short-duration RF ablation, Computer model, Thermal lesion

Posted Date: June 16th, 2021

DOl: https://doi.org/10.21203/rs.3.rs-580584/v1

License: (c) (i) This work is licensed under a Creative Commons Attribution 4.0 International License.

Read Full License 


\section{Thermal and electric characteristics of high-power short- duration radiofrequency ablation and standard radiofrequency ablation: A computer simulation study}

Kaihao $\mathrm{Gu}^{1, *}$, Shengjie Yan ${ }^{1, *, * *}$, Xiaomei $\mathrm{Wu}^{1,2,3,4, * *}$

${ }^{1}$ Center for Biomedical Engineering, School of Information Science and Technology, Fudan University;

${ }^{2}$ Academy for Engineering and Technology, Fudan University, China;

${ }^{3}$ Key Laboratory of Medical Imaging Computing and Computer Assisted Intervention (MICCAI) of Shanghai, Fudan University, China;

${ }^{4}$ Shanghai Engineering Research Center of Assistive Devices, Shanghai, China

*These authors contributed equally to this work.

${ }^{* *}$ Co-Correspondence: Shengjie Yan, E-mail: yanshengjie115@ 163.com

Xiaomei Wu, E-mail: xiaomeiwu@fudan.edu.cn

Tel.: 86-21-65643709-801 


\begin{abstract}
Background: High power-short duration ablation is an emerging conception for cardiac RF treatment. But the biophysical ablation properties of this technique have not been fully explored. This study compared the electric field characteristics and thermal lesion dimension in High power-short duration (HP-SD) radio frequency (RF) ablation and standard RF ablation by using the finite element method.
\end{abstract}

Results: The results demonstrated that the lesion size and temperature in HP-SD RF ablation increased faster than standard RF ablation. The thermal lesion volume in both ablation modes demonstrated a linear increase and the rate of increase of HP-SD RF ablation grew faster than that of standard RF ablation. For HP-SD application at $50 \mathrm{~W}$ for $5 \mathrm{~s}$, the lesion depth was shallower (1.74 to $2.1 \mathrm{~mm}$ vs 2.40 to $3.15 \mathrm{~mm}$ ) and the surface lesion diameter was broader ( 2.76 to $3.32 \mathrm{~mm}$ vs 2.42 to $2.66 \mathrm{~mm}$ ) than that for standard RF ablation at $25 \mathrm{~W}$ for $30 \mathrm{~s}$.

Conclusion: Compared with standard RF ablation, HP-SD RF ablation creates a broader lesion width and surface lesion diameter but shallower lesion depth, with a faster increase in temperature. HP-SD ablation is more able to achieve uniform and contiguous lesion shape, which is a suitable for point-to-point RF ablation procedures. Higher temperature was formed in deeper space of cardiac tissue in HP-SD ablation. The duration of HP-SD ablation should be strictly controlled for preventing the steam occur in tissue.

Keywords: Cardiac RF ablation, High-power short-duration RF ablation, Computer model, Thermal lesion 


\section{Background}

Radiofrequency (RF) catheter ablation is a minimally invasive therapy being widely used for the treatment of various types of atrial fibrillation (AF). Circumferential pulmonary vein isolation (PVI) and left atrial (LA) linear ablation have become basic RF ablation strategies for AF treatment [1,2]. PVI and LA linear ablation were achieved through point-to-point ablation using the standard RF ablation strategy (20-35 W for 20-30 s) [3]. Standard RF application of lower power and longer duration result in greater dissipation of RF energy deep inside of the tissue due to conductive heating. However, conductive heating is difficult to control, potentially causing unexpected collateral tissue damage, such as atrial-esophageal fistulas or steam pop [4]. Therefore, to overcome the weakness of standard RF ablation, high-power short-duration (HP-SD) RF ablation was proposed. HP-SD RF ablation is a current trend in AF treatment that not only shortens the operation time significantly but also creates a suitable lesion depth $[5]$

However, the biophysical ablation properties of HP-SD RF ablation are not fully clear [6], specifically, (1) the characteristics of lesion size and shape created by HP-SD ablation; (2) optimal HP-SD approach parameters have yet not been determined; (3) the potential for char or steam pop (tissue boiling) resulting from increased ablation duration or power; (4) the relationship between the maximum temperature of the myocardium and the formation of thermal lesions; and (5) the area of resistive heating and the distribution of electric field intensity, current density, and power density in HPSD RF ablation. Therefore, the aim of this study was to determine the thermal field characteristics (lesion size and shape) and electric field characteristics generated by HP-SD RF ablation through computer modeling and simulation. A comparison of the ablation features between HP-SD and standard RF ablation was also performed. 


\section{Results}

During RF ablation, the heat absorbed by the myocardium is proportional to power density. Figure 1 shows the power-time curve $(25 \mathrm{~W}$ for $30 \mathrm{~s})$ in the simulation study. The constant power protocol was achieved by manually controlling the applied voltage by trial and error. Figure 2 shows the electric field distribution for standard RF ablation ( $25 \mathrm{~W}$ for $30 \mathrm{~s}$ ) and HP-SD RF ablation ( $50 \mathrm{~W}$ for $5 \mathrm{~s}$ ) at an initial impedance of $108 \Omega$. To better observe the electric field characteristics, a contour line of $15 \mathrm{~V} / \mathrm{mm}$ was used to describe the electric field intensity, a contour line of $2 \mathrm{~mA} / \mathrm{mm}^{2}$ was used to describe the current density, and a contour line of $30 \mathrm{~mW} / \mathrm{mm}^{3}$ was used to describe the power density. Because we considered an isotropic and homogeneous cardiac tissue in the model, the direction of the electric field intensity was consistent with the direction of the current density. Due to the uniform conductivity of the metal electrode and the equipotential of the entire electrode, the electric field intensity inside the metal electrode was zero, which means that the metal electrode itself did not generate heat during ablation. The temperature rise of the metal electrode was caused by only the conductive heat from the tissue to the electrode. The maximum electric field intensity and current density appeared at the electrode-tissue interface, which is the reason that carbonization was likely to occur at the electrode-myocardial contact interface. Power density was equal to the product of the electric field intensity and the current density ( $q=J \cdot E$ ), and it was proportional to the resistive heating area. The results indicated that HP-SD RF ablation was able to create a larger resistance heating area (surrounded by $30 \mathrm{~mW} / \mathrm{mm}^{3}$ ) than standard $\mathrm{RF}$ ablation, and the resistive heating area of $50 \mathrm{~W}$ ablation was approximately twice that of standard $25 \mathrm{~W}$ ablation $\left(3.94 \mathrm{~mm}^{2}\right.$ and 1.74 $\mathrm{mm}^{2}$ for $50 \mathrm{~W}$ for $5 \mathrm{~s}$ and $25 \mathrm{~W}$ for $30 \mathrm{~s}$, respectively). Because the conductivity of the blood $(0.99 \mathrm{~s} / \mathrm{m})$ was 6.18 times that of the myocardium $(0.16 \mathrm{~s} / \mathrm{m})$, the current density 
in the blood was significantly greater than that in the myocardium. Table 1 illustrates the power delivered in the blood and tissue during HP-SD RF ablation and standard RF ablation. We found that at a fixed electrode insertion depth $(0.25 \mathrm{~mm})$, the energy dissipated in the blood was 1.57 times that in the myocardium, whether for standard or HP-SD ablation.

\section{Power vs. Time}

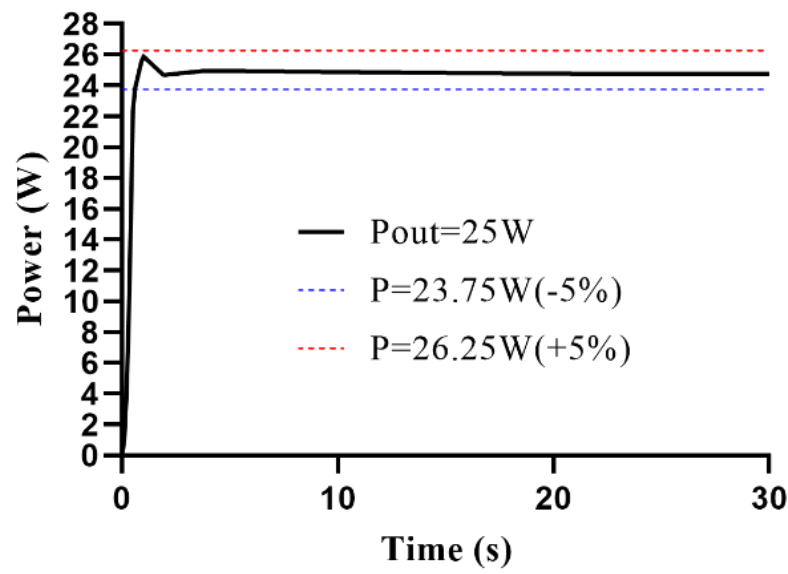

Figure 1. The power-time curve of $25 \mathrm{~W}-30 \mathrm{~s}$ in the simulation study
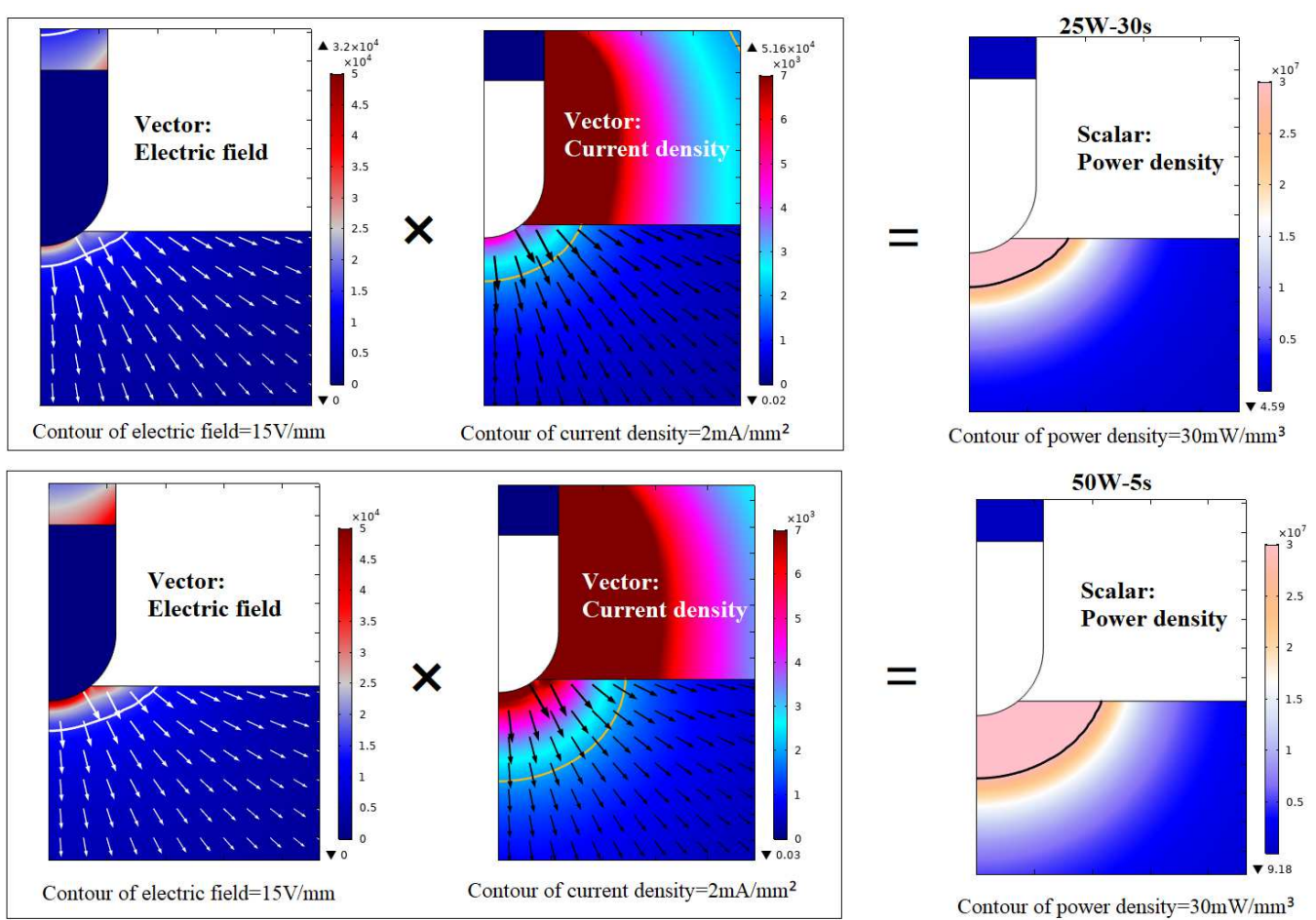

Figure 2. Electric field intensity, current density and power density distribution (the conductivity of the external tissue $=0.1 \mathrm{~S} / \mathrm{m}$; initial impedance $=108 \Omega$ ) 
Table 1. Cross-sectional area of resistive heating $\left(30 \mathrm{~mW} / \mathrm{mm}^{3}\right)$ and power dissipated in the blood and myocardium at an initial impedance of $108 \Omega$

\begin{tabular}{|c|c|c|c|}
\hline $\begin{array}{c}\text { Ablation } \\
\text { mode }\end{array}$ & $\begin{array}{c}\text { The resistive heating } \\
\text { area }\left(30 \mathrm{~mW} / \mathrm{mm}^{3}\right)\end{array}$ & $\begin{array}{c}\text { Power Dissipated } \\
\text { in Blood }\end{array}$ & $\begin{array}{c}\text { Power Dissipated } \\
\text { in Tissues }\end{array}$ \\
\hline $50 \mathrm{~W}-5 \mathrm{~s}$ & $3.94 \mathrm{~mm}^{2}$ & $30.6 \mathrm{~W}$ & $19.4 \mathrm{~W}$ \\
\hline $25 \mathrm{~W}-30 \mathrm{~s}$ & $1.74 \mathrm{~mm}^{2}$ & $15.3 \mathrm{~W}$ & $9.7 \mathrm{~W}$ \\
\hline
\end{tabular}

Three sets of impedance values were tested in the simulation models. Figure 3 shows the temperature distributions of standard RF ablation and HP-SD RF ablation. In atrial tissue, heating the atrial wall in full thickness at a physiologically lethal temperature $\left(\geq 50{ }^{\circ} \mathrm{C}\right.$ ) is usually sufficient, therefore, a $50{ }^{\circ} \mathrm{C}$ isotherm was used to describe lesion shape (the solid black line in Figure 3) in the current study. The geometry of thermal lesions produced with HP-SD RF ablation differed from those produced with standard RF ablation at $25 \mathrm{~W}$ for $30 \mathrm{~s}$. The shape of the lesion for HP-SD ablation was symmetrical and elliptical, whereas the lesion for standard ablation was more circular in shape.

Figure 4 shows the relationship of lesion depth, lesion width, surface lesion diameter and the maximum temperature with initial impedance at three sets of ablation modes. Table 2 illustrates the lesion dimension and the maximum temperature in standard RF ablation (25 W-30 s) and HP-SD RF ablation (50 W-12 s) at three sets of impedance values (108 $\Omega, 117 \Omega$ and $135 \Omega$ ). During the HP-SD RF ablation (50 W-12 s), the lesion width was significantly greater than that of standard ablation ( $25 \mathrm{~W}-30 \mathrm{~s})$. The surface lesion diameter and the maximum temperature generated at high-power ablation $(50 \mathrm{~W}-12 \mathrm{~s})$ were significantly greater than that of standard ablation (25 W-30 s). By comparing the results from the ablation condition of $25 \mathrm{~W}-30 \mathrm{~s}$ with that of $50 \mathrm{~W}-12 \mathrm{~s}$, the percentage increases of the lesion depth, lesion width and surface lesion diameter were $7.3 \%, 17.7 \%$ and $80.4 \%$, respectively when the initial impedance was $108 \Omega$. 


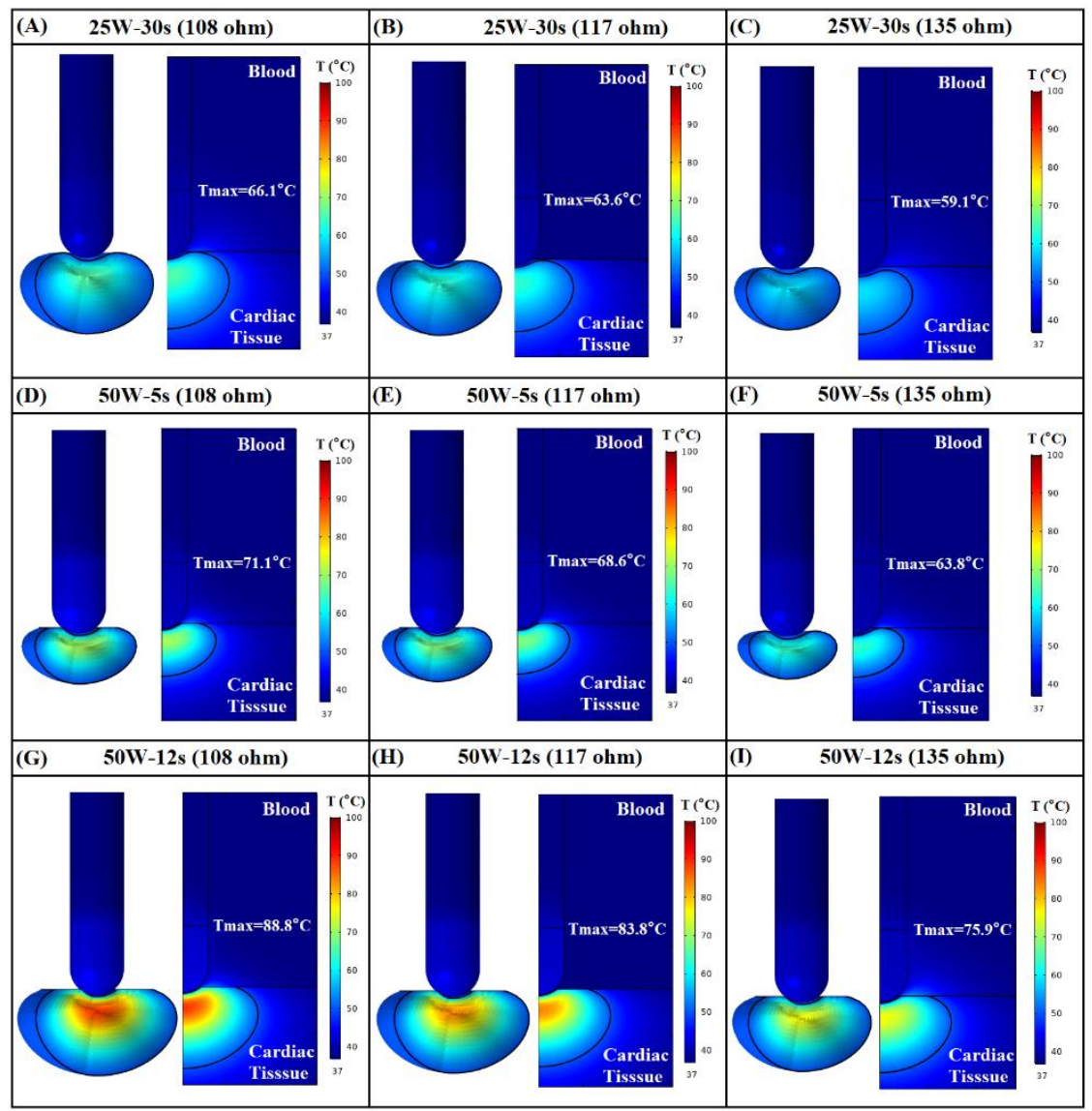

Figure 3. Temperature distributions for standard cardiac RF ablation and HP-SD RF ablation at three sets of initial impedance

(A) Lesion Depth vs. Initial impedance

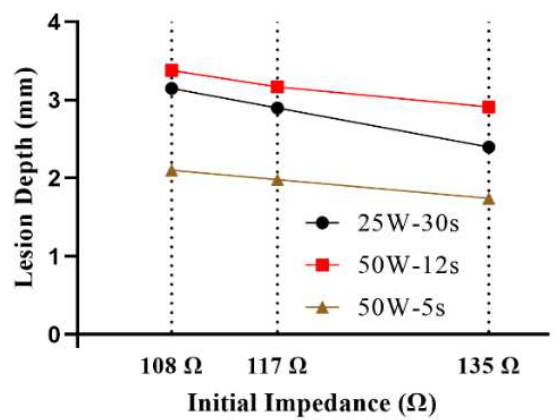

(B) Lesion Width vs. Initial impedance

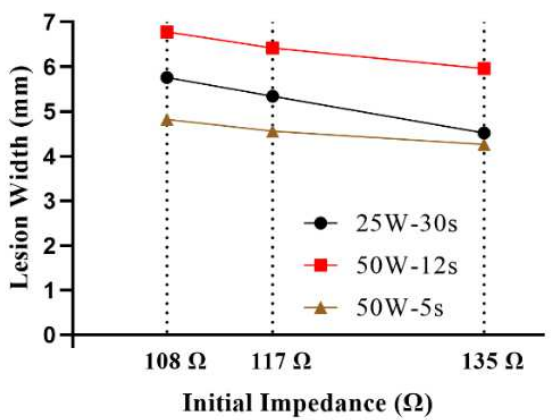

(C) Surface Lesion diameter vs. Intial impedance (D) Maximum Temperature vs. Intial impedance
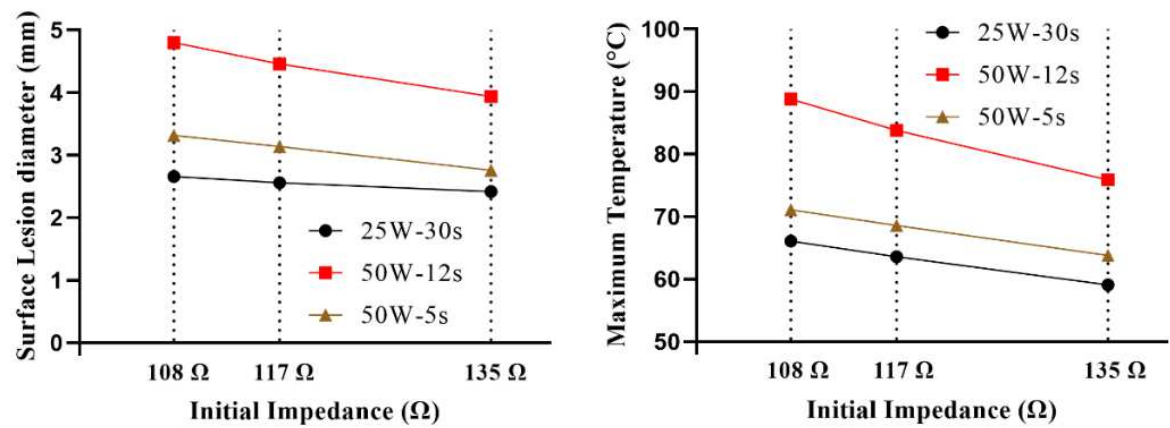

Figure 4. (A) Lesion depth versus initial impedance; (B) lesion width versus initial impedance; (C) surface lesion diameter versus initial impedance; (D) the maximum temperature versus initial impedance 
Table 2. Lesion depth, lesion width, surface lesion diameter, and the maximum temperature for standard RF ablation and HP-SD RF ablation at three sets of impedance.

\begin{tabular}{|c|c|c|c|c|}
\hline \multicolumn{5}{|c|}{ Ablation mode: $25 \mathrm{~W}-30 \mathrm{~s}$} \\
\hline $\begin{array}{c}\text { Initial } \\
\text { impedance }\end{array}$ & Lesion depth & Lesion width & $\begin{array}{c}\text { Surface Lesion } \\
\text { diameter }\end{array}$ & $\begin{array}{c}\text { Maximum } \\
\text { temperature }\end{array}$ \\
\hline $108 \Omega$ & $3.15 \mathrm{~mm}$ & $5.76 \mathrm{~mm}$ & $2.66 \mathrm{~mm}$ & $66.1^{\circ} \mathrm{C}$ \\
\hline $117 \Omega$ & $2.90 \mathrm{~mm}$ & $5.34 \mathrm{~mm}$ & $2.56 \mathrm{~mm}$ & $63.6^{\circ} \mathrm{C}$ \\
\hline $135 \Omega$ & $2.40 \mathrm{~mm}$ & $4.52 \mathrm{~mm}$ & $2.42 \mathrm{~mm}$ & $59.1^{\circ} \mathrm{C}$ \\
\hline \multicolumn{2}{|c|}{ Ablation mode: } & $50 \mathrm{~W}-12 \mathrm{~s}$ & \\
\hline Initial & Lesion depth & Lesion width & $\begin{array}{c}\text { Surface Lesion } \\
\text { diameter }\end{array}$ & $\begin{array}{c}\text { Maximum } \\
\text { temperature }\end{array}$ \\
\hline $108 \Omega$ & $3.38 \mathrm{~mm}$ & $6.78 \mathrm{~mm}$ & $4.80 \mathrm{~mm}$ & $88.8^{\circ} \mathrm{C}$ \\
\hline $117 \Omega$ & $3.17 \mathrm{~mm}$ & $6.42 \mathrm{~mm}$ & $4.46 \mathrm{~mm}$ & $83.8^{\circ} \mathrm{C}$ \\
\hline $135 \Omega$ & $2.91 \mathrm{~mm}$ & $5.96 \mathrm{~mm}$ & $3.94 \mathrm{~mm}$ & $75.9^{\circ} \mathrm{C}$ \\
\hline
\end{tabular}

Compared with the ablation condition of $25 \mathrm{~W}-30 \mathrm{~s}$, the $50 \mathrm{~W}-12 \mathrm{~s}$ one increased the lesion depth, lesion width and surface lesion diameter by $9.3 \%, 20.2 \%$ and $74.2 \%$, respectively when the initial impedance was $117 \Omega$. For the initial impedance of $135 \Omega$, the percentage increases were $21.2 \%, 31.8 \%$ and $62.8 \%$ in lesion depth, width and surface lesion diameter respectively under the same ablation conditions.

Figure 5 presents the curves of lesion depth vs. ablation time, lesion width vs. ablation time, lesion cross-sectional area vs. ablation time and lesion volume vs. ablation time, respectively, at the condition of $108 \Omega$. The lesion cross-sectional area was the area of temperature distribution above $50{ }^{\circ} \mathrm{C}$ as shown in Figure 3. We observed that the lesion depth and width increased faster during the early stage of thermal lesion formation. The rates of increase began to gradually decrease after 3 to $5 \mathrm{~s}$. The thermal lesion volume demonstrated a linear increase and the rate of increase of HP-SD RF ablation grew faster than that of standard RF ablation. Higher power caused bigger lesion width and 

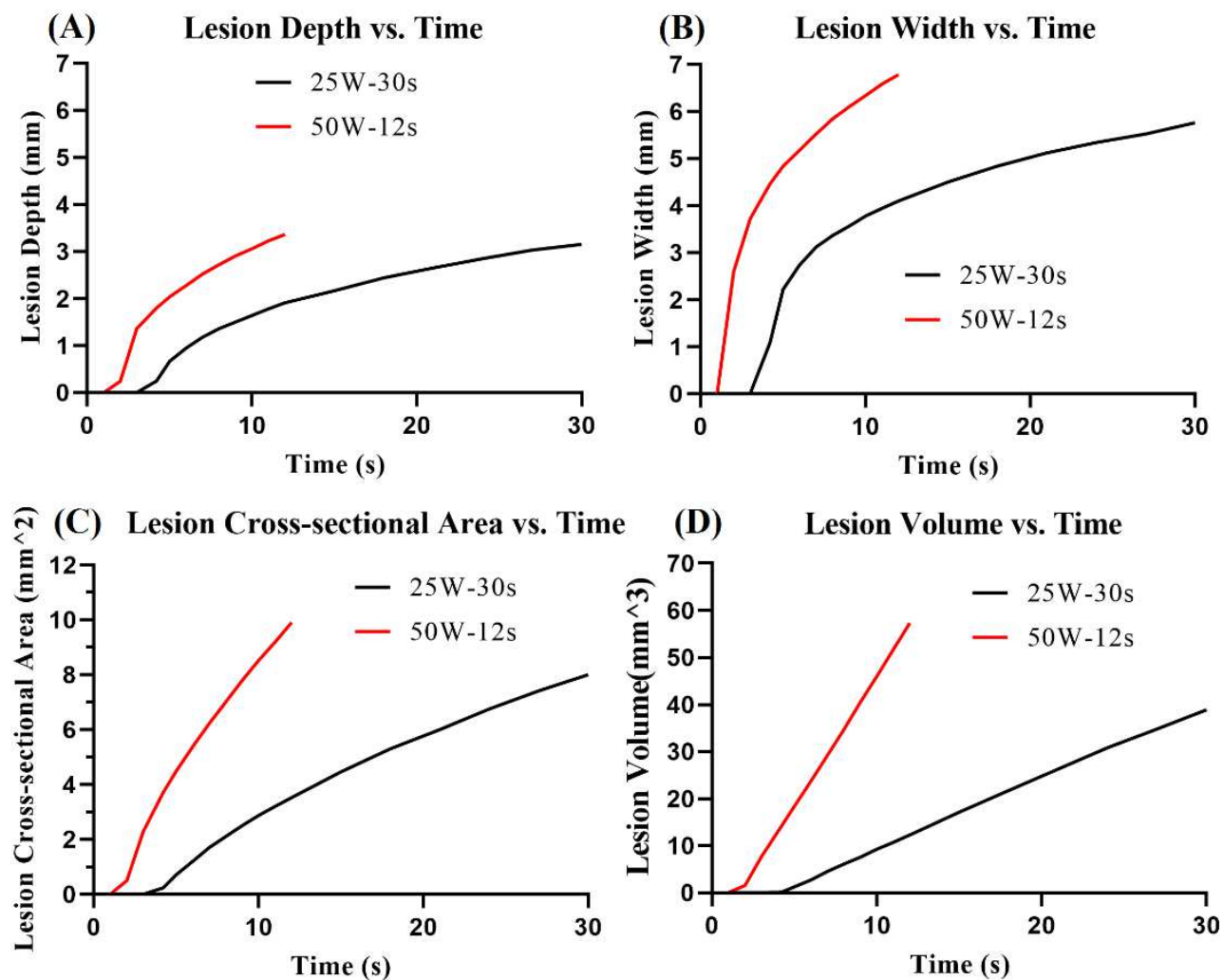

Figure 5. (A) Lesion depth versus ablation time, (B) lesion width versus ablation time, (C) lesion cross-section area versus ablation time, (D) lesion volume versus ablation time

surface lesion diameter, with the fastest increase in lesion size. The lesion volume was greater for RF application with $50 \mathrm{~W}-12 \mathrm{~s}$ than that of $25 \mathrm{~W}-30 \mathrm{~s}\left(57.3 \mathrm{~mm}^{3}\right.$ vs. 38.9 $\mathrm{mm}^{3}$ ), which implied an increase of $47.3 \%$. The results also indicated that HP-SD RF ablation was more likely to create a larger lesion cross-sectional area than standard RF ablation $\left(9.9 \mathrm{~mm}^{2}\right.$ and $8 \mathrm{~mm}^{2}$ for $50 \mathrm{~W}-12 \mathrm{~s}$ and $25 \mathrm{~W}-30 \mathrm{~s}$, respectively, which implied an increase of $23.7 \%$ ).

\section{Discussion}

The main objective of this study was to simulate lesion size and electric characteristics in HP-SD RF ablation and standard RF ablation.

Our observations demonstrated that within the first $5 \mathrm{~s}$ of RF application, shallower and broader lesions were created with HP-SD RF ablation, and the lesion size increased faster than standard RF ablation. In clinical point-to-point ablation, the maximum 
distance between the adjacent two lesion points is commonly limited to within $5 \mathrm{~mm}$ to avoid the occurrence of an ablation gap that may increase the recurrence rate of AF [7]. In HP-SD RF ablation, a lesion width greater than $5 \mathrm{~mm}$ was created, which was better for achieving continuous lesions between adjacent points [8]; a deeper but narrower lesion was created using standard RF ablation ( $25 \mathrm{~W}-30 \mathrm{~s}$ ) compared with HP-SD ablation $(50 \mathrm{~W}-5 \mathrm{~s})$. This lesion characteristic of HP-SD application is particularly useful in AF ablation procedures such as PVI. The larger diameter of HP-SD lesions might contribute to greater contiguity between adjacent lesion points, thereby forming a complete PVI. The reduced lesion depth could also create a transmural lesion in the thin atrial tissue by $50 \mathrm{~W}-5 \mathrm{~s}$ ablation (e.g., $2.1 \mathrm{~mm}, 1.98 \mathrm{~mm}$ and $1.74 \mathrm{~mm}$ for impedance $=108 \Omega, 117 \Omega$ and $135 \Omega$, respectively). Histological studies report that the average LA wall thickness is 1.5 to $2 \mathrm{~mm}$, and the range is 0.5 to $4 \mathrm{~mm}$ [9]. In this study, $50 \mathrm{~W}$ ablation for $12 \mathrm{~s}$ created a lesion depth ranging from 2.91 to $3.38 \mathrm{~mm}$, which indicated that high-power ablation may create transmural lesions in PVI or LA ablation. However, the reduced depth of the lesion caused by HP-SD RF ablation may not be sufficient to create a transmural lesion in areas with increased LA wall thickness. In general, compared with standard RF ablation, a more suitable lesion shape and size was created with HP-SD RF ablation in a few seconds, not only improving efficiency but also reducing the difficulty of catheter operation.

RF ablation lesions were created through resistive heating and conductive heating [10]. Resistive heating in tissue is proportional to the square of the RF current density (the power density) and is the main cause of lesion formation in HP-SD RF ablation. Conductive heating is the direct transfer of thermal energy to deep tissues and is the primary mechanism in standard RF ablation. During resistive heating, the current passed through the tissue and blood surrounding the catheter tip and immediately heated 
the local tissue within the first few millimeters of depth (approximately 1 to $2 \mathrm{~mm}$ ). During the conductive heating phase, a hot source produced by resistance heating passively heats the deeper tissue layer. Conductive heating is time dependent, and the result is determined by the current density and hot source produced in the resistive heating phase. Conductive heating is difficult to control and predict, and a long ablation duration may cause lesion depth of more than $3 \mathrm{~mm}$, resulting in atrial-esophageal fistula or pulmonary vein stenosis. A potential RF ablation strategy for achieving predictable transmural lesion depth is the maximization of resistance heating and the reduction of conductive heating. RF power was increased to $50 \mathrm{~W}$ to deliver immediate resistive heating to the atrial tissue, whereas the ablation duration was reduced to $5 \mathrm{~s}$ to limit collateral tissue damage caused by conductive heating (Figure 3D-F).

One study showed that the use of high-power RF ablation without a reduction of duration improves ablation outcomes but also increases the risk of complications [11]. Our study also found that the temperature exceeded $75^{\circ} \mathrm{C}$ in the cardiac tissue as the duration increased to $12 \mathrm{~s}$ with $50 \mathrm{~W}$ (Table 2). The duration of high-power ablation is a key parameter for creating durable ablation lesions or complications. Although cold saline perfusion can prevent the charring of myocardial surfaces, the RF power dissipated in tissue can also lead to build-up of heat in deeper tissues. Therefore, the ablation duration should be strictly controlled to avoid coagulation, char formation, or overheating in HP-SD ablation. Furthermore, a computer model of ultrashort RF pulse ablation was created by Irastorza et al. to study the effects of thermal latency on lesion depth [12]. They found that the thermal latency phenomenon significantly increased lesion depth after HP-SD RF pulses. According to the thermal latency phenomenon, we can reasonably assert that the ablation duration should be more strictly limited for HP-SD ablation on the posterior wall of the atrium. In addition, due to the rapid 
temperature rise, the power and duration should be strictly controlled in HP-SD RF ablation. Excessive increase in power and duration may result in char or boiling.

Lesion size is a key determinant of ablation outcome. However, in clinical ablation procedure, the lesion size is difficult to be measured. In this study, we modeled a constant power of $25 \mathrm{~W}$ and $50 \mathrm{~W}$, which is the usual ablation mode in standard and HP-SD RF ablation. In the computational model, the impedance between tip electrode and dispersive electrode was tuned to match with the clinical transthoracic impedance range for simulating the real clinical ablation. From the simulation results, the maximum temperature achieved in the myocardium of $50 \mathrm{~W}-12 \mathrm{~s}$ ablation did not exceed $100^{\circ} \mathrm{C}$ and no steam pop occurred in the tissue which was consistent with the observations of clinical results. For example, in one HP-SD RF ablation (50 W) study, a total of $3961 \mathrm{RF}$ ablations were performed in $51 \mathrm{AF}$ patients [13]. The average ablation duration of all lesions was $11.2 \pm 3.7 \mathrm{~s}$ and no steam pops were heard. In another study, Winkle et al. examined the complication rates of HP-SD RF ablation (45-50 W for $2-15 \mathrm{~s}$ ) [14]. At 11,436 ablations, they observed only 2 steam pops in atrial tissue. Although the material properties of the heart model used in our model referred to human instead of animal tissue, our findings still confirm previous studies $[15,16]$, showing that HPSD ablation creates wider but shallower lesions ex vivo and in vivo. The simulation results indicated that under the same ablation condition, the lesion size changed with the initial contact impedance, as shown in Figure 5. Therefore, in real ablation procedure, operator should set the appropriate ablation parameters based on the initial contact impedance. Apart from that, prolonging the duration in HP-SD applications could definitely increase the lesion size (depth, width, and area). A $50 \mathrm{~W}$ ablation for $12 \mathrm{~s}$ produced a lesion depth ranging from 2.91 to $3.38 \mathrm{~mm}$, which is suitable for the ablation of thick cardiac tissue such as mitral isthmus. The maximum 
temperature of $50 \mathrm{~W}$ ablation for $12 \mathrm{~s}$ was significantly higher than that of $25 \mathrm{~W}$ ablation for $30 \mathrm{~s}\left(88^{\circ} \mathrm{C}\right.$ vs $66.1^{\circ} \mathrm{C}$, for $\left.108 \Omega\right)$. The temperature difference $\left(21.9^{\circ} \mathrm{C}\right)$ was due to the increased energy dissipation and reduced cooling duration in HP-SD heating.

This study has certain limitations. First, fluid dynamics was neglected in order to exhibit apparent characteristics of different ablation conditions. The saline irrigation was modeled by applying a fixed temperature on electrode surface, which ignores the period for temperature rise from the ambient temperature. Such simplification could overestimate the blood temperature around the electrode surface [17]. High temperature in blood is a potential cause for thrombus formation [18], it is especially vital for HPSD ablation to avoid any possible overheating. Second, heart beating is an unstable factor in real situation, the insertion of the electrode varies with pacing thus influencing the ablation temperature. Additionally, the selection of ablation parameters for HP-SD ablation as power and duration has not yet achieved a consensus [19]. A comprehensive study including different insertion depth of electrode, cooling effect and ablation parameters might be concerned in future research. Third, the effective ablation lesion was evaluated by the $50^{\circ} \mathrm{C}$ isothermal contour in the current case, however, thermal damage is also related to ablation duration [20], which is one of the key points in HPSD ablation. The Arrhenius model can be an alternative as long as a proper extent for lesion description can be concluded [21]. 


\section{Conclusions}

Compared with standard RF ablation, HP-SD RF ablation creates a broader lesion width and surface lesion diameter but shallower lesion depth, with a faster increase in lesion size and temperature. HP-SD ablation is more able to achieve uniform and contiguous lesion shape, which is suitable for point-to-point RF ablation procedures. Higher temperature was formed in deeper space of cardiac tissue in HP-SD ablation; The duration of high-power ablation should be strictly controlled. 


\section{Methods}

We constructed an electro-thermal coupling model of cardiac RF ablation by finite element method to analyze the temperature distribution and electric field characteristics. In the numerical model, the bio-heat governing equation, electrical and thermal boundary conditions, and material characteristics followed the methods of S Yan et al. 2020, but the RF ablation strategy was different from his method [22].

\section{Bio-heat governing equation}

The physical phenomenon for the electro-thermal coupling problem is governed by bio-heat transfer equation (1) modified by the enthalpy method [23]. $T, \rho, k, q$, and $h$ are the temperature $(\mathrm{K})$, density $\left(\mathrm{kg} / \mathrm{m}^{3}\right)$, thermal conductivity $(\mathrm{W} / \mathrm{m} \mathrm{K})$, power density $\left(\mathrm{W} / \mathrm{m}^{3}\right)$, and enthalpy, respectively, and $Q_{b}$ and $Q_{m}$ represent the heat loss due to blood perfusion $\left(\mathrm{W} / \mathrm{m}^{3}\right)$ and metabolic heat $\left(\mathrm{W} / \mathrm{m}^{3}\right)$, respectively. The term of the metabolic heat production was ignored in our study because it is far smaller than the values of the other variables [24]. The heat loss caused by blood perfusion was also negligible because no large blood vessels exist in the myocardial tissue [25]. The power loss produced by blood flow was modeled with forced thermal convection coefficients in the electrode-blood interface and endocardium-blood interface.

$$
\frac{\partial(\rho h)}{\partial t}=\nabla \cdot(k \nabla T)+q-Q_{b}+Q_{m}
$$

The enthalpy of cardiac tissue is related to tissue temperature as expressed in equation (2) [26]. $\rho_{i}$ and $c_{i}$ are the density and specific heat $(\mathrm{J} / \mathrm{kg} \mathrm{K})$ of cardiac tissue $(\mathrm{i}=1$ before a phase change; $\mathrm{i}=\mathrm{g}$ for post-phase-change), $h_{f g}=2.162 \cdot 10^{9} \mathrm{~J} / \mathrm{m}^{3}$ and $C=75 \%$ are the latent heat and water content, respectively. In our study, the $50^{\circ} \mathrm{C}$ 
isotherm was used to assess the thermal lesion.

$$
\frac{\partial(\rho h)}{\partial t}=\frac{\partial T}{\partial t} \cdot\left\{\begin{array}{cc}
\rho_{l} c_{l} & 0<T \leq 99^{\circ} C \\
h_{f g} C & 99<T \leq 100^{\circ} C \\
\rho_{g} c_{l} & T>100^{\circ} C
\end{array}\right.
$$

At an RF frequency of $500 \mathrm{kHz}$, myocardium is injured by Joule heating through the induction of RF current, and this electrical problem can be expressed in a quasi-static form [27]:

$$
\nabla \cdot(\sigma(T) \nabla V)=0
$$

where $\sigma(T)$ is the electrical conductivity of the myocardium and $V$ is the electric potential. In this study, we used the quasi-static electrical equation to resolve the electro-thermal coupling problem. Accordingly, the direct current voltage corresponding to the root mean squared value of the RF voltage is applied to the electrode, and a zero voltage is applied to the model boundary. We considered constantpower RF ablation, which is commonly used in cardiac RF ablation. In the computer model, the applied voltage was modulated to keep the delivering power constant.

\section{Geometry of the computer model and electrical and thermal boundary conditions}

We developed an electro-thermal coupling model for cardiac RF ablation based on twodimensional axisymmetric geometry. Figure 6A depicts the geometry of the computer model (not to scale), which consists of a fragment of cardiac tissue, connective tissue, blood, and a catheter. Myocardial thickness (H) was $10 \mathrm{~mm}$, catheter diameter (D) was $2.31 \mathrm{~mm}$, and electrode length (L) was $3 \mathrm{~mm}$. The electrode was positioned perpendicular to and against the endocardium at an insertion depth of $0.25 \mathrm{~mm}$. The catheter was surrounded by the blood domain and the connective tissue was located below the myocardium. 


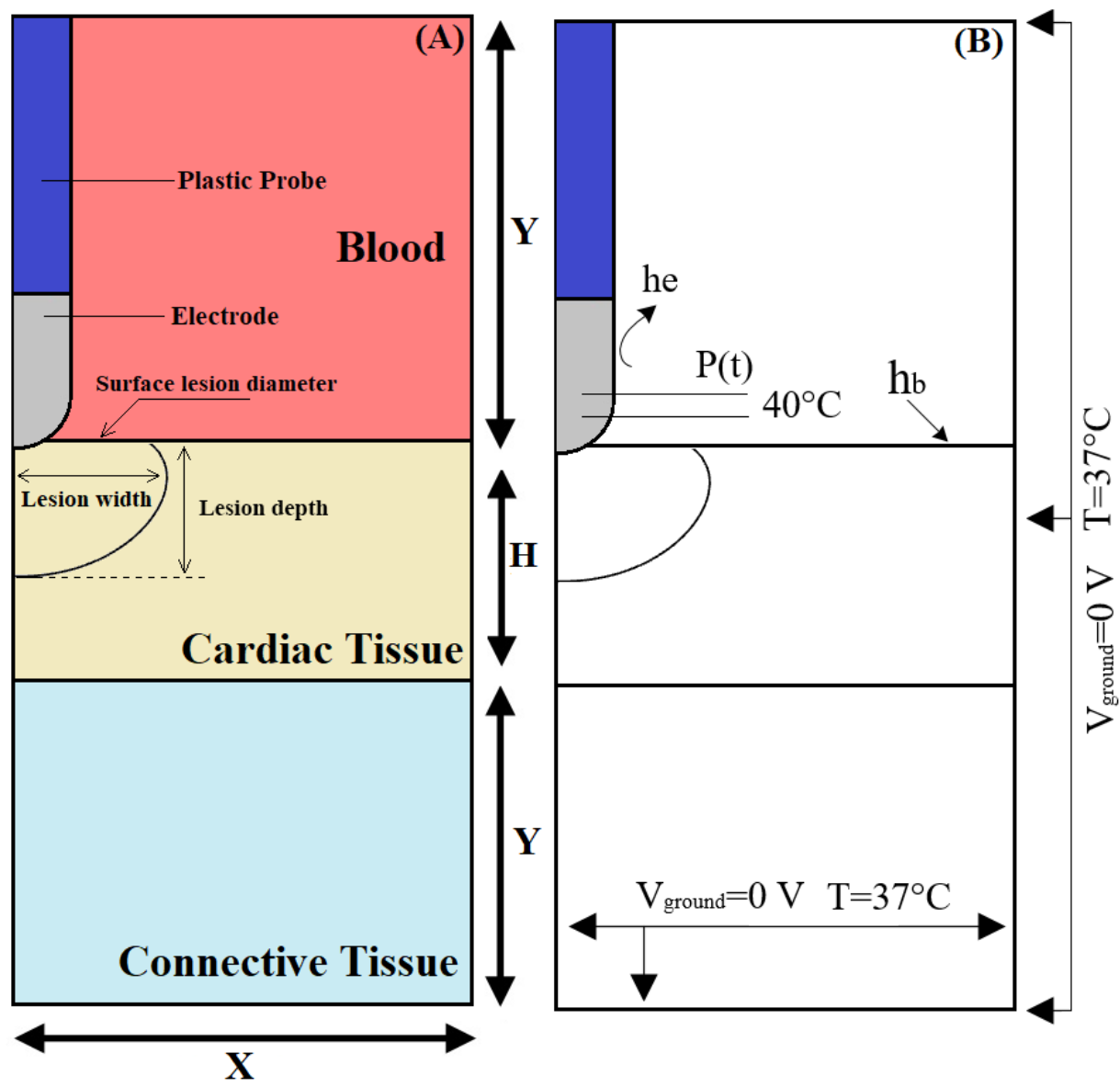

Figure 6. (A) Geometry of computational model (not to scale); (B) electrical and thermal boundary conditions

Figure 6B illustrates the electrical and thermal boundary conditions for cardiac RF ablation. A zero voltage was applied to the boundaries of the model to mimic the electrical performance of the dispersive electrode, and a constant power of $25 \mathrm{~W}$ or 50 W was applied to the active electrode throughout the ablation duration.

In this study, the applied voltage was manually controlled by trial and error to ensure a constant power output [28]. The initial voltage was adjusted to keep the output power close to the predefined value. The global impedance of the model was then calculated at an initial voltage of $50 \mathrm{~V}$. After obtaining the impedance, we then manually calculate the time dependent ablation voltage by Ohm's law as $V=\sqrt{\mathrm{P} \times \mathrm{R}}$, and the value of which was examined to control the error within $\pm 5 \%$ for the constant output power. 
The initial temperatures of all elements and the border of the model were set to $37^{\circ} \mathrm{C}$. The cooling effect produced by blood flow was modeled with two sets of forced thermal convection coefficients, which were applied to the endocardium-blood interface $\left(h_{b}=\right.$ $\left.708 \mathrm{~W} / \mathrm{m}^{2} \mathrm{~K}\right)$ and the blood-electrode interface $\left(\mathrm{h}_{\mathrm{e}}=3636 \mathrm{~W} / \mathrm{m}^{2} \mathrm{~K}\right)$ [29]. A fixed temperature of $40{ }^{\circ} \mathrm{C}$ was applied to the cylindrical zone of the electrode-blood interface to model the effect of saline irrigation, as was noted in previous computational studies $[17,30]$. This temperature value was chosen because it is similar to that obtained by using irrigation electrode in clinical practice [31]. Model dimensions (X and Y), time step, and grid size were determined using convergence analysis to avoid boundary effects. A maximal temperature difference less than $0.5 \%$ in cardiac tissue in consecutive simulations was acting as the control parameter in the convergence tests [26]. The mentioned parameters were determined as: $\mathrm{X}=\mathrm{Y}=220 \mathrm{~mm}$, time step $=0.02$ $\mathrm{s}$, and grid size $=0.2 \mathrm{~mm}$ in the finest zone (electrode-tissue interface). In the study, COMSOL Multiphysics 5.3a was used to create a finite element model and calculate the simulation results.

\section{Material characteristics}

Table 3 lists the material properties in the electro-thermal coupling model. The electrical and thermal conductivity of myocardium was represented as a piecewise function that varied with temperature [32]. As the temperature increased from $37^{\circ} \mathrm{C}$ to $100^{\circ} \mathrm{C}$, the electrical conductivity of myocardium increased exponentially $\left(1.5 \% /{ }^{\circ} \mathrm{C}\right)$ and then decreased with a fourth order mode between $100^{\circ} \mathrm{C}$ and $105^{\circ} \mathrm{C}$. The thermal conductivity of the myocardium increased linearly with temperature $\left(1.2 \% /{ }^{\circ} \mathrm{C}\right)$ up to $100^{\circ} \mathrm{C}$, following which it remained constant.

The conductivity of human myocardium ranges from $0.16-0.33 \mathrm{~S} / \mathrm{m}$, and the 
transthoracic impedance measured by RF generator changes from 90 to $140 \Omega$ in clinical practice [33]. In this simulation study, in order to approach clinical ablation, the initial conductivity of the myocardium was set to $0.16 \mathrm{~S} / \mathrm{m}$, and the conductivity of the external tissue (underneath the myocardium) $\sigma_{0}$ was tuned to match the clinical transthoracic impedance [34]. In our model, the conductivity of external tissue was set as $0.1 \mathrm{~S} / \mathrm{m}, 0.075 \mathrm{~S} / \mathrm{m}$ and $0.05 \mathrm{~S} / \mathrm{m}$, respectively. Therefore, the initial impedance between tip electrode and dispersive electrode was tuned to $108 \Omega, 117 \Omega$ and $135 \Omega$, respectively.

Table 3. Thermal and electrical characteristics of the elements of the numerical models; Measurement temperature at $37^{\circ} \mathrm{C}$.

\begin{tabular}{|c|c|c|c|c|}
\hline Element/material & $\begin{array}{c}\sigma \\
(\mathrm{s} / \mathrm{m})\end{array}$ & $\begin{array}{c}k \\
(\mathrm{~W} / \mathrm{m} \cdot \mathrm{K})\end{array}$ & $\begin{array}{c}\rho \\
\left(\mathrm{kg} / \mathrm{m}^{3}\right)\end{array}$ & $\begin{array}{c}c \\
(\mathrm{~J} / \mathrm{kg} \cdot \mathrm{T})\end{array}$ \\
\hline Electrode & $4.6 \times 10^{6}$ & 71 & 21500 & 132 \\
\hline Plastic Probe & $10^{-5}$ & 0.026 & 70 & 1045 \\
\hline Cardiac Tissue & 0.16 & 0.53 & 1060 & 3111 \\
\hline Blood & 0.99 & 0.54 & 1000 & 4180 \\
\hline $\begin{array}{c}\text { Connective } \\
\text { Tissue }\end{array}$ & $\sigma_{0}$ & 0.39 & 1027 & 2372 \\
\hline
\end{tabular}

$\sigma_{0}$ was tuned to match the clinical transthoracic impedance range (90 to $140 \Omega$ ) 


\section{Abbreviations}

RF: Radiofrequency; AF: Atrial fibrillation; PVI: Pulmonary vein isolation; LA: Left atrium; HP-SD: High power-short duration

\section{Declarations}

Ethics approval and consent to participate

Not applicable

\section{Consent for publication}

Not applicable

\section{Availability of data and materials}

The data used to support the findings of this study are available from the corresponding author upon request and also can be found in the references cited in this paper.

\section{Competing interests}

The authors declare that they have no competing interests

\section{Funding}

This work received financial support from National Natural Science Foundation of China, grant no. 61801123 and 61171009, Shanghai Municipal Commission of economy and information technology, grant no. GYQJ-2018-2-05, and the Shanghai Municipal Science and Technology Major Project, grant no. 2017SHZDZX01 and 16441907900.

\section{Authors' contributions}

KG wrote the manuscript, collected and evaluated the data. SY designed the study, wrote the manuscript and contributed to the analysis of data. XW contributed to the conception, evaluated the resulting data and supervised the proceedings of the study. All authors read and approved the final manuscript.

\section{Acknowledgements}

Not applicable 


\section{Reference}

[1] Wang Y, Liu X, Tan H, et al. Evaluation of linear lesions in the left and right atrium in ablation of longstanding atrial fibrillation. Pacing Clin Electrophysiol. 2013;36(10):1202-1210.

[2] O'Neill MD, Wright M, Knecht S, et al. Long-term follow-up of persistent atrial fibrillation ablation using termination as a procedural endpoint. Eur Heart J. 2009;30(9):1105-1112.

[3] Ariyarathna N, Kumar S, Thomas SP, et al. Role of Contact Force Sensing in Catheter Ablation of Cardiac Arrhythmias. JACC Clin Electrophysiol. 2018;4(6):707-723.

[4] Reddy VY, Dukkipati SR, Neuzil P, et al. Randomized, controlled trial of the safety and effectiveness of a contact force-sensing irrigated catheter for ablation of paroxysmal atrial fibrillation: results of the TactiCath Contact Force Ablation Catheter Study for Atrial Fibrillation (TOCCASTAR) Study. Circulation. 2015;132(10):907-915.

[5] Leshem E, Zilberman I, Tschabrunn CM, et al. High-power and short-duration ablation for pulmonary vein isolation. JACC Clin Electrophysiol. 2018;4(4):467-479.

[6] Patel PJ, Padanilam BJ. High-power short-duration ablation: Better, safer, and faster? J Cardiovasc Electrophysiol. 2018;29(11):1576-1577.

[7] Naomi K, Takeshi K, Satoru S, et al. Optimal Lesion Size Index to Prevent Conduction Gap during Pulmonary Vein Isolation. J Cardiovasc Electrophysiol. 2018;29(12):1616-1623.

[8] Pambrun T, Durand C, Constantin M, et al. High-Power (40-50 W) Radiofrequency Ablation Guided by Unipolar Signal Modification for Pulmonary Vein Isolation. Circ Arrhythm Electrophysiol. 2019;12(6):e007304.

[9] Cabrera JA, Ho SY, Climent V, Sanchez-Quintana D. The architecture of the left lateral atrial wall: a particular anatomic region with implications for ablation of atrial fibrillation. Eur Heart $\mathbf{J}$. $2008 ; 29(3): 356-362$.

[10] Haines DE. The Biophysics of Radiofrequency Catheter Ablation in the Heart: The Importance of Temperature Monitoring. Pacing Clin Electrophysiol. 1993;16(3):586-591.

[11] Raja DC, Sanders P, Pathak RK. How much is enough: An appraisal of High-power Short Duration Radiofrequency Ablation for Pulmonary Vein Isolation. J Cardiovasc Electrophysiol. 2019;30(5):2205-2208.

[12] Irastorza RM, D'Avila A, Berjano E. Thermal latency adds to lesion depth after application of highpower short-duration radiofrequency energy: Results of a computer-modeling study. J Cardiovasc 
Electrophysiol. 2018;29(2):322-327.

[13] Winkle RA, Moskovitz R, Hardwin Mead R, et al. Atrial fibrillation ablation using very short duration 50?W ablations and contact force sensing catheters. J Interv Card Electrophysiol. 2018;52(1):1-8.

[14] Winkle RA, Mohanty S, Patrawala RA, et al. Low complication rates using high power (45-50 W) for short duration for atrial fibrillation ablations. Heart Rhythm. 2019,16(2):165-169.

[15] Ali-Ahmed F, Goyal V, Patel M, et al. High-power, low-flow, short-ablation duration-the key to avoid collateral injury? J Interv Card Electrophysiol. 2019;55(1):9-16.

[16] Abhishek B, William C, Jim P, et al. Five seconds of 50-60 W radio frequency atrial ablations were transmural and safe: an in vitro mechanistic assessment and force-controlled in vivo validation. Europace. 2019;19(5):874-880.

[17] Gonzalez-Suarez A, Prez JJ, Berjano E. Should fluid dynamics be included in computer models of RF cardiac ablation by irrigated-tip electrodes? Biomed Eng Online. 2018;17(1):43.

[18] Demolin JM, Eick OJ, Muench K, et al. Soft thrombus formation in radiofrequency catheter ablation. Pacing Clin Electrophysiol. 2002;25(8):1219-1222.

[19] Ücer E, Jungbauer C, Hauck C, et al. The low acute effectiveness of a high-power short duration radiofrequency current application technique in pulmonary vein isolation for atrial fibrillation. Cardiol J. 2020.

[20] Zhang B, Moser MAJ, Zhang EM, et al. A review of radiofrequency ablation: Large target tissue necrosis and mathe- matical modelling. Phys Med. 2016;32(8):961-971.

[21] Chang IA. Considerations for Thermal Injury Analysis for RF Ablation Devices. Open Biomed Eng J. 2010;4(2):3-12.

[22] Yan S, Gu K, Wu X, Wang W. Computer simulation study on the effect of electrode-tissue contact force on thermal lesion size in cardiac radiofrequency ablation. Int J Hyperthermia. 2020;37(1):3748.

[23] Penns HH. Analysis of tissue and arterial blood temperatures in the resting human forearm. J Appl Physiol. 1948;1(2):93-122.

[24] Yan S, Wu X, Wang W. A simulation study to compare the phase-shift angle radiofrequency ablation mode with bipolar and unipolar modes in creating linear lesions for atrial fibrillation ablation. Int J Hyperthermia. 2016;32(3):231-238. 
[25] Yan S, Wu X, Wang W. Theoretical and experimental analysis of amplitude control ablation and bipolar ablation in creating linear lesion and discrete lesions for treating atrial fibrillation. Int $\mathbf{J}$ Hyperthermia. 2017;33(6):608-616.

[26] Gonzalez-Suarez A, Trujillo M, Koruth J, et al. Radiofrequency cardiac ablation with catheters placed on opposing sides of the ventricular wall: Computer modelling comparing bipolar and unipolar modes. Int J Hyperthermia. 2014;30(6):372-384.

[27] Doss JD. Calculation of electric fields in conductive media. Med Phys. 1982;9(4):566-573.

[28] Haemmerich D, Webster JG. Automatic control of finite element models for temperature-controlled radiofrequency ablation. Biomed Eng Online. 2005;42(4):1-8.

[29] Schutt D, Berjano EJ, Haemmerich D. Effect of electrode thermal conductivity in cardiac radiofrequency catheter ablation: A computational modeling study. Int $\mathrm{J}$ Hyperthermia. 2009;25(2):99-107.

[30] Gonzalez-Suarez A, Prez JJ, Berjano E. Computer Modeling of Irrigated-tip Electrodes During RF Cardiac Ablation: Comparative Analysis between Including and Excluding the Problem of Fluid Dynamics. Computing in Cardiology Conference. 2017.

[31] Winterfield JR, Jensen J, Gilbert T, et al. Lesion Size and Safety Comparison Between the Novel Flex Tip on the FlexAbility Ablation Catheter and the Solid Tips on the ThermoCool and ThermoCool SF Ablation Catheters. J Cardiovasc Electrophysiol. 2016;27(1):102-109.

[32] Trujillo M, Berjano E. Review of the mathematical functions used to model the temperature dependence of electrical and thermal conductivities of biological tissue in radiofrequency ablation. Int J Hyperthermia. 2013;29(6):590-597.

[33] Sulkin MS, Laughner JI, Hilbert S, et al. Novel Measure of Local Impedance Predicts CatheterTissue Contact and Lesion Formation. Circ Arrhythm Electrophysiol. 2018;11(4):e005831.

[34] Petras A, Leoni M, Guerra JM, et al. A computational model of open-irrigated radiofrequency catheter ablation accounting for mechanical properties of the cardiac tissue. Int J Numer Method Biomed Eng. 2019;35(11):e3232. 